\title{
Possible Role of Exogenous Melatonin and Melatonin-Receptor-Agonists in the Treatment of Menopause-Associated Sleep Disturbances
}

\author{
Amnon Brzezinski \\ Department of Obstetrics and Gynecology, Hadassah-Hebrew University Medical Center, Jerusalem, Israel \\ Email: amnonbrz@gmail.com
}

Received 27 February 2014; revised 20 March 2014; accepted 28 March 2014

Copyright (C) 2014 by author and Scientific Research Publishing Inc. This work is licensed under the Creative Commons Attribution International License (CC BY). http://creativecommons.org/licenses/by/4.0/ c) (i) Open Access

\begin{abstract}
One of the core symptoms of the menopausal transition is sleep disturbance. Peri-menopausal women often complain of difficulties initiating and/or maintaining sleep with frequent nocturnal and early morning awakenings. Factors that may play a role in this type of insomnia include vasomotor symptoms and changing reproductive hormone levels, circadian rhythm abnormalities, primary insomnia, mood disorders, coexistent medical conditions, and lifestyle. Exogenous melatonin reportedly induces drowsiness and sleep, and may ameliorate sleep disturbances, including the nocturnal awakenings associated with old age and the menopausal transition. Recently, more potent melatonin analogs with prolonged effects and slow-release melatonin preparations have been developed. The melatonergic receptor ramelteon is a selective melatonin-1 (MT1) and melatonin-2 (MT2) receptor agonist with negligible affinity for other neuronal receptors, including gamma-aminobutyric acid and benzodiazepine receptors. It was found effective in increasing total sleep time and sleep efficiency, as well as in reducing sleep latency, in insomnia patients. The melatonergic antidepressant agomelatine, displaying potent MT1 and MT2 melatonergic agonism and relatively weak serotonin 5HT2C receptor antagonism, reportedly is effective in the treatment of depression associated insomnia. This article presents the currently available evidence regarding the effects of these compounds on sleep quality and their possible use in menopause associated sleep disturbances.
\end{abstract}

\section{Keywords}

Melatonin; Melatonin Agonists; Menopause; Sleep; Insomnia; Ramelteon; Agomelatine 


\section{Introduction}

Women have a greater risk for developing insomnia than men [1] [2]. Studies have shown that $25 \%$ of women aged between 50 and 64 years report sleep problems, and 15\% of those report severe sleep disturbance that has a substantial effect on their quality of life [3]. Data from the Study of Women's Health Across the Nation (SWAN) indicate that approximately 70\% of women report Vaso Motor Symptoms (VMS) at some point during the menopausal transition. Approximately $30 \%$ to $40 \%$ of midlife women report sleep disturbance [4].

Women frequently cite VMS at night as the source of this sleep disturbance [5], and epidemiologic investigations using questionnaire measures of VMS and sleep show VMS to be a consistent correlate of reported sleep disturbance. Troubled sleeping seems to be worse in postmenopausal compared with premenopausal women, and significantly worse in surgically postmenopausal compared with naturally postmenopausal women.

Although most epidemiologic studies have found increased reports of sleep disturbance at menopause, this has not been confirmed by laboratory sleep studies. Thus, complaints of poor sleep in menopausal women could also reflect an age-related increase in the prevalence of primary sleep disorders. It has been reported that primary sleep disorders (apnea and restless legs syndrome) are common in this population, however, amelioration of hot flashes may reduce some complaints of poor sleep but will not necessarily alleviate underlying primary sleep disorders [6].

Estrogen and progesterone are involved in a number of brain functions, including sleep [3]. Sex steroid receptors are found in multiple brain areas that are involved in sleep. However, the relationship between hormone replacement therapy (HRT) use and sleep quality is controversial. A recent study showed that stopping HRT led to a moderate increase in sleep difficulties in women aged 45 - 80 years. Use of HRT led to self-reported improved sleep in a large prospective and omised placebo-controlled study of older postmenopausal women [5].

Other hormones that also may play a role in the regulation of sleep include cortisol and melatonin. Circadian rhythm training and maintaining a fixed sleep-wake cycle with adequate sleep duration is an important strategy in improving sleep quality. Melatonin assists in establishing and maintaining the circadian rhythm and sleep, as discussed in details in the next paragraphs.

In humans, the circadian rhythm of melatonin release from the pineal gland is highly synchronized with the habitual hours of sleep, and the daily onset of melatonin secretion is well correlated with the onset of the steepest increase in nocturnal sleepiness ("sleep gate") [7] [8]. Serum melatonin levels were reported to be significantly lower (and the time of peak melatonin values was delayed) in elderly subjects with insomnia compared with age-matched subjects with no insomnia [9]. Exogenous melatonin reportedly induces drowsiness and sleep, and may ameliorate sleep disturbances, including the nocturnal awakenings associated with old age [10] [11]. However existing studies on the hypnotic efficacy of melatonin have been highly heterogeneous in regard to inclusion and exclusion criteria, measures to evaluate insomnia, doses of the medication, and routes of administration. Adding to this complexity, there continues to be considerable controversy over the meaning of the discrepancies that sometimes exist between subjective and objective (polysomnographic) measures of good and bad sleep [12].

Thus, attention has been focused either on the development of more potent melatonin analogs with prolonged effects or on the design of prolonged-release melatonin preparations [13] [14]. The MT [1] and MT [2] melatonergic receptor ramelteon [15] [16] was effective in increasing total sleep time and sleep efficiency, as well as in reducing sleep latency, in insomnia patients [17]. The melatonergic antidepressant agomelatine, displaying potent MT [1] and MT [2] melatonergic agonism and relatively weak serotonin 5HT(2C) receptor antagonism [18], was found effective in the treatment of depression associated insomnia [19]-[22]. Other melatonergic compounds are currently developed [23] [24].

\section{Exogenous Melatonin}

Melatonin's two well-established physiological effects-promotion of sleep and entrainment of circadian rhythms - are both mediated by two specific receptor proteins in the brain, and not by the gamma-aminobutyric acid (GABA) receptors through which most hypnotic agents act. This difference probably explains why, unlike the GABA-agonist drugs, which are true "sleeping pills", exogenous melatonin does not suppress rapid eye movement (REM) sleep nor, in general, affect the distribution of sleep stages [25].

Measurements of melatonin in body fluids in elderly subjects have convincingly demonstrated an age-related impairment of nocturnal pineal melatonin synthesis [26]-[28]. Melatonin production declines with menopause 
and increasing age, and is lower in middle-aged and women with insomnia [29]. Several studies have shown the importance of melatonin both for the initiation and for maintenance of sleep [30]. In all diurnal animals and in human beings, the onset of melatonin secretion coincides with the timing of increase in nocturnal sleep propensity [31].

In 2005 a meta-analysis [32] of 17 studies, involving 284 subjects, that satisfied inclusion criteria demonstrated a significant decrease in sleep latency and significant increases in sleep efficiency and total sleep duration. The inclusion criteria were that a study include at least six subjects, all adults, be randomized and doubleblinded, involve placebo-controlled clinical trials, and use objective measures of sleep evaluation. Studies could utilize crossover or parallel group designs; however, case reports were excluded. Statistical significance was obtained in spite of considerable variations among the studies in melatonin doses and routes of administration, the general health of the subjects, and the measures used to evaluate sleep.

The effects of exogenous melatonin on sleep have been examined under three types of experimental conditions in relation to the onset or offset of endogenous melatonin secretion.

In some studies, the hormone was administered during the daily light period, such that blood melatonin levels would be transiently elevated but would then return to baseline before the initiation of nocturnal melatonin secretion. Such experiments were used to demonstrate that melatonin decreases sleep latency at any time in the afternoon or evening, and that this effect is independent of an action on sleep rhythms (since no treatment can immediately shift the phase of a circadian rhythm by $8-10 \mathrm{hr}$ ).

In others, the hormone was given close enough to the onset of darkness for blood melatonin levels to still be elevated when nocturnal melatonin secretion started. The period during which plasma melatonin levels were continuously elevated would thus be prolonged. Such experiments reflected the use of melatonin to decrease sleep latency and maintain continuous sleep in, for example, a shift-worker or eastbound world traveler who needed to start sleeping earlier.

In yet others, the hormone was given at the end of the light period to older insomniacs with low night-time plasma melatonin levels. The intent was to prolong the portion of the night during which their plasma melatonin concentrations would be in the same range as those of noninsomniac young adults.

In all these situations, oral melatonin decreased sleep latency and, when tested, increased sleep duration and sleep efficiency. A $0.3 \mathrm{mg}$ dose was either as effective as, or more effective than, [25] higher doses, particularly when the hormone was administered for several days. This dose had no effect on body temperature, affirming that, while pharmacologic doses can cause hypothermia, melatonin's ability to promote sleep is not mediated by such a change, as had been suggested. The hormone had no consistent effect on sleep architecture (e.g., REM time). Its effects differed from those of most hypnotic drugs, since after receiving melatonin, subjects could readily keep from falling asleep if they chose so, and their cognitive abilities the next morning were unchanged or improved.

In a study of 30 people [25] who were 50 yr old or older and did or did not suffer from clinically significant insomnia (i.e., sleep efficiencies of $70 \%-80 \%$ in the insomniacs vs. $92 \%$ in controls), melatonin was found to produce statistically and clinically significant improvements in sleep efficiency among insomniacs.

In yet another meta-analysis [33] published at the same year (2005), the authors found that melatonin decreased sleep onset latency (-11.7 minutes; $95 \%$ confidence interval [CI]: $-18.2,-5.2)$; it was decreased to a greater extent in people with delayed sleep phase syndrome ( -38.8 minutes; 95\% CI: $-50.3,-27.3 ; \mathrm{n}=2)$ compared with people with insomnia $(-7.2$ minutes; $95 \%$ CI: $-12.0,-2.4 ; n=12)$. The former result appears to be clinically important. However they conclude that melatonin is not effective in treating most primary sleep disorders with short-term use (4 weeks or less) but that there was evidence to suggest that melatonin was effective in treating delayed sleep phase syndrome with short-term use.

A meta-analysis published in 2009 [34] focused on exogenous melatonin for sleep problems in individuals with intellectual disability. Nine studies (including a total of 183 individuals with intellectual disabilities) showed that melatonin treatment decreased sleep latency by a mean of 34 minutes $(p<0.001)$, increased total sleep time by a mean of 50 minutes ( $p<0.001$ ), and significantly decreased the number of wakes per night $(p<0.05)$. The authors concluded that melatonin decreases sleep latency and number of wakes per night, and increases total sleep time in individuals with intellectual disabilities.

Although in all the above studies about $30 \%-50 \%$ of the participants were women the issue of menopauseassociated insomnia was not specifically addressed. 


\section{Melatonin Receptors Agonists}

Because melatonin has a short half-life ( $<30 \mathrm{~min})$, its efficacy in promoting and maintaining sleep has not been uniform in the studies undertaken so far. Thus, the need for the development of prolonged release preparations of melatonin or of melatonin agonists with a longer duration of action on sleep regulatory structures in the brain arose [35].

In accordance with this idea slow release forms of melatonin were developed [13] (e.g., $\operatorname{Circadin}^{\mathrm{R}}$, a 2-mg preparation developed by Neurim, Tel Aviv, Israel, and approved by the European Medicines Agency in 2007). Their efficacy in treatment of sleep disorders in various populations were recently reported [36].

Also recently, a small series of peri-menopausal women with insomnia treated with mirtazapine followed by prolonged-release melatonin, was published [37]. The author reported that sleep quality ratings improved significantly (by $103 \%$ on average) during combined mirtazapine and prolonged release melatonin (Circadin ${ }^{\mathrm{R}}$ ) intake and $180 \%$ during subsequent intake of prolonged-release melatonin alone or together with very low doses of mirtazapine. Well-being significantly improved by $83 \%$ during the treatment. No adverse events were reported.

A "sleep-switch" model to describe the regulation of sleep wakefulness was originally proposed by Saper and his colleagues [38] [39]. It consists of "flip-flop" reciprocal inhibitions among sleep-associated activities in the ventrolateralpreoptic nucleus and wakefulness-associated activities in the locus coeruleus, dorsal raphe, and tuberomammilary nuclei. The SCN has an active role both in promoting wakefulness as well as in promoting sleep, and this depends upon a complex neuronal network and a number of neurotransmitters released (GABA, glutamate, arginine vasopressin, somatostatin, etc.) [40] [41].

The high density of melatonin receptors in the hypothalamic suprachiasmatic nuclei (SCN) [42] [43] may suggest that melatonin affects sleep and the sleep-wakefulness cycle by acting on these receptors. Thus, the need arose for the development of melatonin receptors agonists with a longer duration of action, and hopefully more potent in affecting sleep quality. The melatonin analogs ramelteon, agomelatine, tasimelteon, and TK-301 are examples of this strategy.

\subsection{Ramelteon}

Ramelteon (Rozerem ${ }^{\mathrm{R}}$; Takeda Pharmaceuticals, Osaka, Japan) is a melatonergic hypnotic analog that has beendemonstrated to be effective in clinical trials. It is atricyclic synthetic analog of melatonin with the chemicalname of (S)-N-[2-(1,6,7,8-tetrahydro-2H-indeno[5,4-b]furan-8-yl)-ethyl]propionamide. In 2005, ramelteon was approved by the USA Food and Drug Administration (FDA) for treatment of insomnia. It is a selective agonist for MT1/MT2 receptors without significant affinity forother receptor sites [44] [45]. In vitro binding studies have shown that ramelteon affinity for MT1 and MT2 receptorsis 3 - 16 times higher than that of melatonin. The selectivity of ramelteon for MT1 has been found to be greater than that of MT2 receptors. The selectivity of MT1 receptors by ramelteon may suggest that it targets sleep onset more specifically than melatonin itself [46] [47]).

Ramelteon is administered usually by the oral route and is absorbed rapidly by the gastrointestinal tract [48]. The half-life of circulating ramelteon is in the range of $1-2 \mathrm{hr}$ which is much longer than that of melatonin. The influence of age and gender on the pharmacokinetics and the pharmacodynamics of ramelteon was evaluated in healthy volunteers (young, 18 - 34 yr; elderly 63 - 79 yr) after administration of a single dose of ramelteon. Compared with young individuals, the clearance of ramelteon was significantly reduced in elderly individuals. No significant effect of gender was observed [49].

Ramelteon is metabolized mainly in the liver via oxidation to hydroxyl and carbonyl groups and then conjugated with glucuronide [50]. Cytochrome P450 (CPY) 1A2 is the majorhepatic enzyme involved in ramelteon metabolism. Four principal metabolites of ramelteon (M-I, M-II, M-III, M-IV) have been identified [51]. Among these, M-II has been found to occur in a much higher concentration with systemic levels of 20- to 100 -fold greater than those of ramelteon itself.

Although the activity of M-II is 30-fold lower than that of ramelteon, its exposure exceeds that of ramelteon by a factor of 30. Hence, it is suggested that M-II may contribute significantly to the net clinical effect of ramelteon intake. Although MT1 and MT2 receptors are widely distributed in the brain outside of the SCN [52][55], the high density of melatonin receptors in the SCN and their relationship to the circadian pacemaker function are highly suggestive of a SCN melatonin receptor role in sleep regulation. Ramelteon specificity for MT1 and MT2 melatonin receptors indicates that its probable sleep related site of action is in the SCN.

Ramelteon may accelerate sleep onset by influencing the hypothalamic sleep switch downstream the SCN in 
the same way as melatonin [56] [57]. Ramelteon promotes sleep onset through the inhibition of SCN electrical activity and the consequent inhibition of circadian wake signal thereby activating the specific sleep-circuit pathway.

Ramelteon's efficacy as hypnotic drug was evaluated in a group of freely moving monkeys (Macacafascicularis) incomparison with that of melatonin and zolpidem [56]. Ramelteon and melatonin were administered in doses of $0.003,0.03$, and $0.3 \mathrm{mg} / \mathrm{kg}$ and $0.3,1$, and $3 \mathrm{mg} / \mathrm{kg}$, respectively, to independent groups of animals. Zolpidem was administered in doses $1,3,10$, or $30 \mathrm{mg} / \mathrm{kg}$ to a third group of monkeys. All drugs were administered orally at 18:00 hr, and the polysomnographic (PSG) recording of sleep was continuously taken from 17:00 to 7:00 hr. Ramelteon at a dose of 0.03 or $0.3 \mathrm{mg} / \mathrm{kg}$ significantly reduced sleep onset latency (SOL) for both light sleep and NREM sleep as Melatonin and its analogs in insomnia and depression compared to controls. Both doses of ramelteon increased total sleep time (TST), whereas the lowest dose employed $(0.003 \mathrm{mg} / \mathrm{kg})$ was ineffective. Melatonin administration at a $0.3 \mathrm{mg} / \mathrm{kg}$ dose significantly reduced latency to SOL for light sleep but not for NREM sleep [58]. At a dose of $1 \mathrm{mg}$ and $3 \mathrm{mg} / \mathrm{kg}$, melatonin tended to shorten SOL and increased TST, but these changes were marginally significant. The administration of zolpidem ( 1 - $30 \mathrm{mg} / \mathrm{kg})$ did not produce any significant effect on SOL or TST at any of the doses tested. From these results, it was concluded that ramelteon has apotent sleep inducing effect not shared by either melatoninor zolpidem [59].

In a double-blind study including 829 insomniac patients (mean age $72.4 \mathrm{yr}$ ), ramelteon, at a dose of 4 - 8 mg/day, brought about a significant $16 \%$ - 35\% reduction in SOL [60]. TST was increased by both doses of ramelteon. In another randomized, multicenter double-blind, placebo-controlled crossover study including 107 patients followed by PSG, ramelteon was administered in doses of 4 - $32 \mathrm{mg} /$ day [61]. The treatment decreased latency to first sleep (LFS) and increased TST significantly.

A short-term evaluation of the efficacy of ramelteon was performed in 100 elderly subjects by administering 4 and $8 \mathrm{mg}$ doses in a two night/three day period crossover design [62]. LPS decreased, and TST and SE augmented as compared to placebo. Likewise, the efficacy of ramelteonin reducing SOL and in increasing TST and SE was evaluated in 405 patients administered with $8 \mathrm{mg}$ or $16 \mathrm{mg}$ of ramelteon for $5 \mathrm{wk}$ in a double-blind placebo-controlled study [62]. The results confirmed the effect of ramelteon to reduce SOL and to increase SE and TST [62].

Ramelteon's hypnotic action (at an $8 \mathrm{mg}$ dose) was sorapid that it caused significant reductions in SOL within a week (63\% for ramelteon versus $39.7 \%$ for placebo, $P<0.001)$ [63]. This reduction in LPS was sustained throughout the 5 wk of study (63\% and $65.9 \%$ ramelteon versus $41.2 \%$ and $48.9 \%$ placebo at the end of the 3rd and 5th wk, respectively) [62].

Dobkin et al. conducted a small, prospective open-label trial of ramelteon in 20 healthy peri- and postmenopausal women with insomnia, using an $8 \mathrm{mg}$ dose [63]. Their results showed significant improvements in latency to sleep onset, total sleep time and daytime functioning using qualitative reporting measures.

In yet another 6-month-long study performed in 451 adults suffering from chronic insomnia drawn from different centers across the globe (mainly USA, Europe, Russia and Australia), ramelteon consistently reduced LPS when compared with placebo [64]. The baseline LPS decreased from 70.7 to $32.0 \mathrm{~min}$ at week 1 (with ramelteon) and this reduction in LPS was maintained at months $1,3,5$, and 6 . No adverse effects, like next morning residual effects, rebound insomnia, or with drawal effects, were noted [64].

In a double-blind placebo-controlled study involving a large number of Japanese patients with chronic insomnia $(\mathrm{N}=1130)$, the efficacy and safety of 4 and $8 \mathrm{mg}$ ramelteon were evaluated [65]. At a $4 \mathrm{mg}$ dose of ramelteon, nostatistically significant differences were found in subjective SOL as compared to the placebo group, while with $8 \mathrm{mg}$ of ramelteon, a significant increase in TST and a decrease in SOL were observed. The same investigators evaluated the efficacy and safety of ramelteon in 190 Japanese adults with chronic insomnia treated for a period of $24 \mathrm{wk}$ [66]. TST significantly increased with an $8 \mathrm{mg} /$ day dose of ramelteon, and this was maintained for 20 wk. In this study, ramelteon was well tolerated and did not cause residual effects, rebound insomnia, with drawal symptoms, or dependence after 24 wk of continuous treatment [66].

Summarizing Ramelteon's studies, it seems that in all clinical studies undertaken (in various doses ranging from $4 \mathrm{mg}$ to $32 \mathrm{mg} /$ day) in patients with chronic insomnia, the drug reduced SOL and increased sleep duration [67] without significant adverse effects.

\subsection{Agomelatine}

Disturbances in sleep are prominent features of depression. Antidepressant drugs that are also effective in alle- 
viating sleep disturbances can be of better therapeutic value in treating depressive disorders [68]. It is suggested that an ideal antidepressant should not only decrease sleep onset difficulties and wakefulness after sleep onset but should also promote the feelings of freshness and alertness during daytime [69].

Antidepressants are often prescribed for hot flushes [70]. Studies have shown 50\% - 60\% reduction in symptoms with both fluoxetine and venlafaxine [71]. These medications may be especially beneficial for those with vasomotor symptoms and mood symptoms. Other serotonin-modulatingantide pressants, such as trazodoneand nefazodone, have been prescribed for insomnia and depression-related insomnia with good results [72].

The newly introduced melatonergic antidepressant agomelatine (Valdoxan; Servier, Neuilly-sur-Seine, France) is endowed with these properties. Agomelatine, a naphthalenic compound chemically designated as N-(2-[7methoxy-1-naphthalenyl]ethyl) acetamide, acts on both MT1and MT2 melatonergic receptors and also acts as an antagonist to $5-\mathrm{HT}_{2 \mathrm{C}}$ receptors at a three orders of magnitude greater concentration [73]. It does not show any significant affinities for muscarinic, histaminergic, adrenergic, and dopaminergic receptor subtypes [74].

Agomelatine has been licensed by European Medicines Agency (EMEA) for the treatment of major depressive disorder (MDD). In several animal models of depression like the forced swimming test, the learned helplessness model [75], and the social stress model [76], agomelatine displayed antidepressant activity. It has been hypothesized that agomelatine has a unique mechanism of action because its effects are mediated through MT1/MT2 melatonergic receptors and 5- $\mathrm{HT}_{2 \mathrm{C}}$ serotonergic receptors, acting differently at different circadian phases of the day/night cycle [77]. Through this dual action, agomelatine may promote and maintain sleep at night and helps to maintain alertness during daytime.

Agomelatine given before sleep would have an immediate sleep promoting melatonergic effect that would prevail over its potentially anti-hypnotic $5 \mathrm{HT}_{2 \mathrm{C}}$ antagonism [78]. In contrast, during the day, the drug's 5- $\mathrm{HT}_{2 \mathrm{C}}$ antagonism would predominate over the melatonergic action, thus having an alerting action. $5-\mathrm{HT}_{2 \mathrm{C}}$ receptors are concentrated in frontal cortex, amygdala, hippocampus, and cortico-limbic structures that are involved in the regulation of mood and cognition [79]. They are also present in the SCN [80], and antidepressants, while exerting their therapeutic effects, decrease the number of SCN 5- $\mathrm{HT}_{2 \mathrm{C}}$ receptors in those structures [81].

One criticism of this dual interpretation of agomelatine action is the large differences in affinity for the putative action on serotonergic receptors as compared to the melatonergic one (about three orders of magnitude greater concentration are needed to exert $5-\mathrm{HT}_{2 \mathrm{C}}$ antagonism) [73].

Moreover, both melatonin and ramelteon have been shown to display antidepressant-like effects even though they are not reportedly known to affect serotonergic activity significantly [82]-[84].

As agomelatine addresses sleep disturbances as well as depressive symptoms and has early onset of action even in a severely depressed population, it stands unique among the antidepressants for effective management of MDD [70]. Because sleep disturbances constitute one of the prominent features of depressive illness and are among the diagnostic criteria of DSM-IV, it is not strange that the melatonergic activity of agomelatine (or ramelteon) could be beneficial for this symptom [85]. Patients suffering from MDD or bipolar disorder exhibit marked difficulties in initiation and maintenance of sleep, poor quality of sleep and frequent nocturnal, and early morning wakening [68].

The American National Institute of Mental Health (NIMH) Epidemiological Catchment Area (ECA) study of sleep disturbances and psychiatric disorders identified sleep disturbances as a highly significant risk factor forsubsequent development of depression [86].

The effectiveness of agomelatine in reducing the sleep complaints of depressed patients has been evaluated. Altered intra-night temporal distribution of REM sleep with increased amounts of early REM sleep and reductionin SOL to REM sleep is the specific EEG sleep patterns that are associated with depression [87]. Hence, prevention of persistent sleep disturbances would help to reduce the risk of relapse or recurrence of depressive disorders. The treatment of depressive patients with agomelatine for 6 wk increased the duration of NREM sleep without affecting REM sleep thereby causing improvements in both sleep quality and continuity [88]. In the study that compared the effect of ago melatine $(25 \mathrm{mg}$ ) with the antidepressant venlafaxine, ago melatine promoted sleep earlier and scored higher on the criteria of getting into sleep as assessed by the Leeds Sleep Evaluation Questionnaire [89]. The improvement in sleep quality was evident from first week of treatment with agomelatine, whereas venlafaxine did not produce any beneficial effect. This can be important clinically in as much as improvement in sleep disturbances often precede that of depressive symptoms [90]-[92]. Agomelatine has also been shown effective in reducing circadian rhythm disturbances seen in MDD [93]. 


\section{Discussion and Summary}

The data presented above clearly indicate that exogenous melatonin and its various analogs promote and maintain sleep. However, there is inconsistency and discrepancy among the large number of reports regarding the degree of efficacy and the clinical significance of these effects. The results of endogenous melatonin's action in insomnia have not been consistent probably because the studies described in existing publications on melatonin's efficacy have utilized different inclusion and exclusion criteria, different outcome measures to evaluate insomnia, different doses of the hormone, and different routes and timing of its administration. There also continues to be considerable controversy over the meaning of the discrepancies that sometimes exist between subjective and objective (polysomnographic) measures of good and bad sleep. Adding to this complexity is melatonin's short half-life and ready metabolism after oral administration of fast release preparations. Hence, prolonged released melatonin preparations and melatonin agonists were introduced and have shown good results in treating insomnia.

It should be noted that very recently an official regulatory-the European Food Safety Authority (EFSA) has evaluated the available evidence that melatonin can reduce the time it takes for normal sleepers and patients with insomnia to fall asleep [94]. It concluded that there is evidence that "a cause and effect relationship exists between the consumption of melatonin and reduction of sleep onset latency $\cdots$ ", and that " $\cdots 1 \mathrm{mg}$ of melatonin should be consumed close to bedtime...”.

Also, a recent consensus of the British Association for Psychopharmacology on evidence-based treatment of insomnia, parasomnia, and circadian rhythm sleep disorders concluded that melatonin is the first-choice treatment when a hypnotic is indicated in patients over 55 yr [95].

These recommendations also apply for peri/post-menopausal women who suffer from insomnia. However, further investigations by randomized controlled studies to evaluate the efficacy of these interventions in this specific sub-population are warranted.

\section{References}

[1] Phillips, B.A., Collop, N.A., Drake, C., Consens, F., Vgontzas, A.N. and Weaver, T.E. (2008) Sleep Disorders and Medical Condition in Women. Proceedings of the Women and Sleep Workshop, National Sleep Foundation, Washington DC, 5-6 March 2007, Journal of Women's Health, Larchmt, 17, 1191-1199. http://dx.doi.org/10.1089/jwh.2007.0561

[2] Ameratunga, D., Goldin, J. and Hickey, M. (2012) Sleep Disturbance in Menopause. Internal Medicine Journal, 42, 742-747. http://dx.doi.org/10.1111/j.1445-5994.2012.02723.x

[3] Polo-Kantola, P. (2011) Sleep Problems in Midlife and Beyond. Maturitas, 68, 224-232. http://dx.doi.org/10.1016/j.maturitas.2010.12.009

[4] Gold, E., Colvin, A., Avis, N., et al. (2006) Longitudinal Analysis of Vasomotor Symptoms and Race/Ethnicity across the Menopausal Transition: Study of Women's Health across the Nation (SWAN). American Journal of Public Health, 96, 1226-1235. http://dx.doi.org/10.2105/AJPH.2005.066936

[5] Kravitz, H.M., Zhao, X., Bromberger, J.T., et al. (2008) Sleep Disturbance during the Menopausal Transition in a Multi-Ethnic Community Sample of Women. Sleep, 31, 979-990.

[6] Freedman, R.R. and Roehrs, T.A. (2007) Sleep Disturbance in Menopause. Menopause, 14, 826-829. http://dx.doi.org/10.1097/gme.0b013e3180321a22

[7] Brzezinski, A. (1997) Melatonin in Humans. New England Journal of Medicine, 336, 186-195. http://dx.doi.org/10.1056/NEJM199701163360306

[8] Shochat, T., Haimov, I. and Lavie, P. (1998) Melatonin: The Key to the Gate of Sleep. Annals of Medicine, 30, 109114. http://dx.doi.org/10.3109/07853899808999392

[9] Haimov, I., Lavie, P., Laudon, M., Herer, P., Vigder, C. and Zisapel, N. (1995) Melatonin Replacement Therapy of Elderly Insomniacs. Sleep, 18, 598-603.

[10] Zhdanova, I.V., Lynch, H.J. and Wurtman, R.J. (1997) Melatonin—A Sleep-Promoting Hormone. Sleep, 20, 899-907.

[11] Zhdanova, I.V. and Friedman, L. (2002) Melatonin for Treatment of Sleep and Mood Disorders. In: Mischolon, D. and Rosenbaum, J., Eds., Natural Medications for Psychiatric Disorders: Considering the Alternatives, Williams\& Wilkins, 147-174.

[12] Nowell, P.D., Mazumdar, S., Buysse, D.J., Dew, M.A., Reynolds, C.F. and Kupfer, D. (1997) Benzodiazepines and Zolpidem for Chronic Insomnia: A Meta-Analysis of Treatment Efficacy. JAMA, 278, 2170-2177. 
http://dx.doi.org/10.1001/jama.1997.03550240060035

[13] Lemoine, P., Nir, T., Laudon, M. and Zisapel, N. (2007) Prolonged-Release Melatonin Improves Sleep Quality and Morning Alertness in Insomnia Patients Aged 55 Years and Older and Has No Withdrawal Effects. Journal of Sleep Research, 16, 372-380. http://dx.doi.org/10.1111/j.1365-2869.2007.00613.x

[14] Lemoine, P. and Zisapel, N. (2012) Prolonged-Release Formulation of Melatonin (Circadin) for the Treatment of Insomnia. Expert Opinion on Pharmacotherapy, 13, 895-905. http://dx.doi.org/10.1517/14656566.2012.667076

[15] Kato, K., Hirai, K., Nishiyama, K., et al. (2005) Neurochemical Properties of Ramelteon (TAK-375), a Selective MT1/ MT2 Receptor Agonist. Neuropharmacology, 48, 301-310. http://dx.doi.org/10.1016/j.neuropharm.2004.09.007

[16] Miyamoto, M. (2009) Pharmacology of Ramelteon, a Selective $\mathrm{MT}_{1} / \mathrm{MT}_{2}$ Receptor Agonist: A Novel Therapeutic Drug for Sleep Disorders. CNS Neuroscience \& Therapeutics, 15, 32-51. http://dx.doi.org/10.1111/j.1755-5949.2008.00066.x

[17] Pandi-Perumal, S.R., Srinivasan, V., Spence, D.W., Moscovitch, A., Hardeland, R., Brown, G.M. and Cardinali, D.P. (2009) Ramelteon: A Review of Its Therapeutic Potential in Sleep Disorders. Advances in Therapy, 26, 613-626. http://dx.doi.org/10.1007/s12325-009-0041-6

[18] Millan, M.J., Gobert, A., Lejeune, F., Dekeyne, A., Newman-Tancredi, A., Pasteau, V., Rivet, J.M. and Cussac, D. (2003)

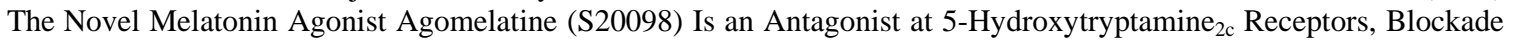
of Which Enhances the Activity of Frontocortical Dopaminergic and Adrenergic Pathways. Journal of Pharmacology and Experimental Therapeutics, 306, 954-964. http://dx.doi.org/10.1124/jpet.103.051797

[19] Srinivasan, V., Cardinali, D.P., Pandi-Perumal, S.R. and Brown, G.M. (2011) Melatonin Agonists for Treatment of Sleep and Depressive Disorders. Journal of Experimental and Integrative Medicine, 1, 149-158.

[20] Kennedy, S.H. and Emsley, R. (2006) Placebo-Controlled Trial of Agomelatinein the Treatment of Major Depressive Disorder. European Neuropsychopharmacology, 16, 93-100. http://dx.doi.org/10.1016/j.euroneuro.2005.09.002

[21] Llorca, P.M. (2010) The Antidepressant Agomelatine Improves the Quality of Life of Depressed Patients: Implications for Remission. Journal of Psychopharmacology, 24, 21-26. http://dx.doi.org/10.1177/1359786810372978

[22] Srinivasan, V., De Berardis, D., Shillcutt, S.D. and Brzezinski, A. (2012) Role of Melatonin in Mood Disorders and the Antidepressant Effects of Agomelatine. Expert Opinion on Investigating Drugs, 10, 22-1503.

[23] Rajaratnam, S.M., Polymeropoulos, M.H., Fisher, D.M., Roth, T., Scott, C., Birznieks, G. and Klerman, E.B. (2009) Melatonin Agonist Tasimelteon (VEC-162) for Transient Insomnia after Sleep-Time Shift: Two Randomised Controlled Multicentre Trials. Lancet, 373, 482-491. http://dx.doi.org/10.1016/S0140-6736(08)61812-7

[24] Zemlan, F.P., Mulchahey, J.J., Scharf, M.B., Mayleben, D.W., Rosenberg, R. and Lankford, A. (2005) The Efficacy and Safety of the Melatonin Agonist Beta-Methyl-6-Chloromelatonin in Primary Insomnia: A Randomized, PlaceboControlled, Crossover Clinical Trial. Journal of Clinical Psychiatry, 66, 384-390. http://dx.doi.org/10.4088/JCP.v66n0316

[25] Zhdanova, I.V., Wurtman, R.J., Regan, M.M., Taylor, J.A., Shi, J.P. and Leclair, O.U. (2001) Melatonin Treatment for Age-Related Insomnia. The Journal of Clinical Endocrinology \& Metabolism, 86, 4727-4730. http://dx.doi.org/10.1210/jcem.86.10.7901

[26] Haimov, I., Laudon, M., Zisapel, N., Souroujon, M., Nof, D., Shlitner, A., Herer, P., Tzischinsky, O. and Lavie, P. (1994) Sleep Disorders and Melatonin Rhythms in Elderly People. British Medical Journal, 309, 167. http://dx.doi.org/10.1136/bmj.309.6948.167

[27] Hughes, R.J. and Badia, P. (1997) Sleep-Promoting and Hypothermic Effects of Daytime Melatonin Administration in Humans. Sleep, 20, 124-131.

[28] Leger, D., Laudon, M. and Zisapel, N. (2004) Nocturnal 6-Sulfatoxymelatonin Excretion in Insomnia and Its Relation to the Response to Melatonin Replacement Therapy. American Journal of Medicine, 116, 91-95. http://dx.doi.org/10.1016/j.amjmed.2003.07.017

[29] Vakkuri, O., Kivela, A., Leppaluoto, J., Valtonen, M. and Kauppila, A. (1996) Decrease in Melatonin Precedes FollicleStimulating Hormone Increase during Perimenopause. European Journal of Endocrinology, 135, 188-192. http://dx.doi.org/10.1530/eje.0.1350188

[30] Cajochen, C., Jewett, M.E. and Dijk, D.J. (2003) Human Circadian Melatonin Rhythm Phase Delay during a Fixed Sleep-Wake Schedule Interspersed with Nights of Sleep Deprivation. Journal of Pineal Research, 35, 149-157. http://dx.doi.org/10.1034/j.1600-079X.2003.00072.x

[31] Lavie, P. (1997) Melatonin: Role in Gating Nocturnal Rise in Sleep Propensity. Journal of Biological Rhythms, 12, 657-665. http://dx.doi.org/10.1177/074873049701200622

[32] Brzezinski, A., Vangel, M.G., Wurtman, R.J., Norrie, G., Zhdanova, I., Ben-Shushan, A. and Ford, I. (2005) Effects of Exogenous Melatonin on Sleep: A Meta-Analysis. Sleep Medicine Reviews, 9, 41-50. 
http://dx.doi.org/10.1016/j.smrv.2004.06.004

[33] Buscemi, N., Vandermeer, B., Hooten, N., Pandya, R., Tjosvold, L., Hartling, L., Baker, G., Klassen, T.P. and Vohra, S. (2005) The Efficacy and Safety off Exogenous Melatonin for Primary Sleep Disorders: A Meta-Analysis. Journal of General Internal Medicine, 20, 1151-1158. http://dx.doi.org/10.1111/j.1525-1497.2005.0243.x

[34] Braam, W., Smits, M.G., Didden, R., Korzilius, H., Van Geijlswijk, I.M. and Curfs, L.M. (2009) Exogenous Melatonin for Sleep Problems in Individuals with Intellectual Disability: A Meta-Analysis. Developmental Medicine \& Child Neurology, 51, 340-349. http://dx.doi.org/10.1111/j.1469-8749.2008.03244.x

[35] Turek, F.W. and Gillette, M.U. (2004) Melatonin, Sleep, and Circadian Rhythms: Rationale for Development of Specific Melatonin Agonists. Sleep Medicine, 5, 523-532. http://dx.doi.org/10.1016/j.sleep.2004.07.009

[36] Garfinkel, D., Zorin, M., Wainstein, J., Matas, Z., Laudon, M. and Zisapel, N. (2011) Efficacy and Safety of Prolonged-Release Melatonin in Insomnia Patients with Diabetes: A Randomized, Double-Blind, Crossover Study. Diabetes, Metabolic Syndrome and Obesity: Targets and Therapy, 4, 307-313.

[37] Dolev, Z. (2011) Case Series of Perimenopausal Women with Insomnia Treated with Mirtazapine Followed by Prolonged-Release Melatonin Add-On and Monotherapy. Archives of Women's Mental Health, 14, 269-273. http://dx.doi.org/10.1007/s00737-011-0205-7

[38] Saper, C.B., Lu, J., Chou, T.C. and Gooley, J. (2005) The Hypothalamic Integrator for Circadian Rhythms. Trends in Neurosciences, 28, 152-157. http://dx.doi.org/10.1016/j.tins.2004.12.009

[39] Saper, C.B., Scammell, T.E. and Lu, J. (2005) Hypothalamic Regulation of Sleep and Circadian Rhythms. Nature, 437, 1257-1263. http://dx.doi.org/10.1038/nature04284

[40] Kalsbeek, A., Perreau-Lenz, S. and Buijs, R.M. (2006) A Network of (Autonomic) Clock Outputs. Chronobiology International, 23, 521-535. http://dx.doi.org/10.1080/07420520600651073

[41] Reghunandanan, V. and Reghunandanan, R. (2006) Neurotransmitters of the Suprachiasmatic Nuclei. Journal of Circadian Rhythms, 4, 2. http://dx.doi.org/10.1186/1740-3391-4-2

[42] Reppert, S.M., Weaver, D.R. and Ebisawa, T. (1994) Cloning and Characterization of a Mammalian Melatonin Receptor that Mediates Reproductive and Circadian Responses. Neuron, 13, 1177-1185. http://dx.doi.org/10.1016/0896-6273(94)90055-8

[43] Dubocovich, M.L., Delagrange, P., Krause, D.N., Sugden, D., Cardinali, D.P. and Olcese, J. (2010) International Union of Basic and Clinical Pharmacology. LXXV. Nomenclature, Classification, and Pharmacology of G Protein-Coupled Melatonin Receptors. Pharmacological Reviews, 62, 343-380. http://dx.doi.org/10.1124/pr.110.002832

[44] Kato, K., Hirai, K., Nishiyama, K., Uchikawa, O., Fukatsu, K., Ohkawa, S., Kawamata, Y., Hinuma, S. and Miyamoto, M. (2005) Neurochemical Properties of Ramelteon (TAK-375), a Selective $\mathrm{MT}_{1} / \mathrm{MT}_{2}$ Receptor Agonist. Neuropharmacology, 48, 301-310. http://dx.doi.org/10.1016/j.neuropharm.2004.09.007

[45] Miyamoto, M. (2009) Pharmacology of Ramelteon, a Selective $\mathrm{MT}_{1} / \mathrm{MT}_{2}$ Receptor Agonist: A Novel Therapeutic Drug for Sleep Disorders. CNS Neuroscience \& Therapeutics, 15, 32-51.

http://dx.doi.org/10.1111/j.1755-5949.2008.00066.x

[46] Cajochen, C. (2005) TAK-375 Takeda. Current Opinion in Investigational Drugs, 6, 114-121.

[47] Greenblatt, D.J., Harmatz, J.S. and Karim, A. (2007) Age and Gender Effects on the Pharmacokinetics and Pharmacodynamics of Ramelteon, a Hypnotic Agent Acting via Melatonin Receptors $\mathrm{MT}_{1}$ and $\mathrm{MT}_{2}$. Journal of Clinical Pharmacology, 47, 485-496. http://dx.doi.org/10.1177/0091270006298602

[48] Stevenson, S., Bryson, S., Amayke, D. and Hibberd, M. (2004) Study to Investigate the Absolute Bioavailability of a Single Oral Dose of Ramelteon (TAK-375) in Healthy Male Subjects. Clinical Pharmacology \& Therapeutics, 75, 22.

[49] Wu, Y.H., Zhou, J.N., Balesar, R., Unmehopa, U., Bao, A., Jockers, R., Van Heerikhuize, J. and Swaab, D.F. (2006) Distribution of $\mathrm{MT}_{1}$ melatonin Receptor Immune-Reactivity in the Human Hypothalamus and Pituitary Gland: Colocalization of $\mathrm{MT}_{1}$ with Vasopressin, Oxytocin, and Corticotropin-Releasing Hormone. Journal of Comparative Neurology, 499, 897-910. http://dx.doi.org/10.1002/cne.21152

[50] Savaskan, E., Olivieri, G., Meier, F., Brydon, L., Jockers, R., Ravid, R., Wirz-Justice, A. and Muller-Spahn, F. (2002) Increased Melatonin 1a-Receptor Immunoreactivity in the Hippocampus of Alzheimer's Disease Patients. Journal of Pineal Research, 32, 59-62. http://dx.doi.org/10.1034/j.1600-079x.2002.00841.x

[51] Savaskan, E., Ayoub, M.A., Ravid, R., Angeloni, D., Fraschini, F., Meier, F., Eckert, A., Muller-Spahn, F. and Jockers, R. (2005) Reduced Hippocampal MT2 Melatonin Receptor Expression in Alzheimer's Disease. Journal of Pineal Research, 38, 10-16. http://dx.doi.org/10.1111/j.1600-079X.2004.00169.x

[52] Savaskan, E., Jockers, R., Ayoub, M., Angeloni, D., Fraschini, F., Flammer, J., Eckert, A., Muller-Spahn, F. and Meyer, P. (2007) The $\mathrm{MT}_{2}$ Melatonin Receptor Subtype Is Present in Human Retina and Decreases in Alzheimers Disease. Current Alzheimer Research, 4, 47-51. http://dx.doi.org/10.2174/156720507779939823 
[53] Brunner, P., Sozer-Topcular, N., Jockers, R., Ravid, R., Angeloni, D., Fraschini, F., Eckert, A., Müller-Spahn, F. and Savaskan, E. (2006) Pineal and Cortical Melatonin Receptors $\mathrm{MT}_{1}$ and $\mathrm{MT}_{2}$ Are Decreased in Alzheimer's Disease. European Journal of Histochemistry, 50, 311-316.

[54] Pandi-Perumal, S.R., Srinivasan, V., Spence, D.W., Moscovitch, A., Hardeland, R., Brown, G.M. and Cardinali, D.P. (2009) Ramelteon: A Review of Its Therapeutic Potential in Sleep Disorders. Advances in Therapy, 26, 613-626. http://dx.doi.org/10.1007/s12325-009-0041-6

[55] Srinivasan, V., Pandi-Perumal, S.R., Trahkt, I., Spence, D.W., Poeggeler, B., Hardeland, R. and Cardinali, D.P. (2009) Melatonin and Melatonergic Drugs on Sleep: Possible Mechanisms of Action. International Journal of Neuroscience, 119, 821-846. http://dx.doi.org/10.1080/00207450802328607

[56] Yukuhiro, N., Kimura, H., Nishikawa, H., Ohkawa, S., Yoshikubo, S. and Miyamoto, M. (2004) Effects of Ramelteon (TAK-375) on Nocturnal Sleep in Freely Moving Monkeys. Brain Research, 1027, 59-66. http://dx.doi.org/10.1016/j.brainres.2004.08.035

[57] France, C.P., Weltman, R.H., Koek, W., Cruz, C.M. and Mcmahon, L.R. (2006) Acute and Chronic Effects of Ramelteon in Rhesus Monkeys (Macaca mulatta): Dependence Liability Studies. Behavioral Neuroscience, 120, 535-541. http://dx.doi.org/10.1037/0735-7044.120.3.535

[58] Roth, T., Seiden, D., Sainati, S., Wang-Weigand, S., Zhang, J. and Zee, P. (2006) Effects of Ramelteon On PatientReported Sleep Latency in Older Adults with Chronic Insomnia. Sleep Medicine, 7, 312-318. http://dx.doi.org/10.1016/j.sleep.2006.01.003

[59] Erman, M., Seiden, D., Zammit, G., Sainati, S. and Zhang, J. (2006) An Efficacy, Safety, and Dose-Response Study of Ramelteon in Patients with Chronic Primary Insomnia. Sleep Medicine, 7, 17-24. http://dx.doi.org/10.1016/j.sleep.2005.09.004

[60] Roth, T., Seiden, D., Wang-Weigand, S. and Zhang, J. (2007) A 2-Night,3-Period, Crossover Study of Ramelteon’s Efficacy and Safety in Older Adults with Chronic Insomnia. Current Medical Research and Opinion, 23, 1005-1014. http://dx.doi.org/10.1185/030079907X178874

[61] Zammit, G., Erman, M., Wang-Weigand, S., Sainati, S., Zhang, J. and Roth, T. (2007) Evaluation of the Efficacy and Safety of Ramelteon in Subjects with Chronic Insomnia. Journal of Clinical Sleep Medicine, 3, 495-504.

[62] Mini, L., Wang-Weigand, S. and Zhang, J. (2008) Ramelteon 8 mg/d versus Placebo in Patients with Chronic Insomnia: Post Hoc Analysis of a 5-Week Trial Using 50\% or Greater Reduction in Latency to Persistent Sleep as a Measure of Treatment Effect. Clinical Therapeutics, 30, 1316-1323. http://dx.doi.org/10.1016/S0149-2918(08)80056-2

[63] Dobkin, R.D., Menza, M., Bienfait, K.L., Allen, L.A., Marin, H. and Gara, M.A. (2009) Ramelteon for the Treatment of Insomnia in Menopausal Women. Post Reproductive Health, 15, 13-18. http://dx.doi.org/10.1258/mi.2009.009002

[64] Mayer, G., Wang-Weigand, S., Roth-Schechter, B., Lehmann, R., Staner, C. and Partinen, M. (2009) Efficacy and Safety of 6-Month Nightly Ramelteon Administration in Adults with Chronic Primary Insomnia. Sleep, 32, 351-360.

[65] Uchimura, N., Ogawa, A., Hamamura, M., Hashimoto, T., Nagata, H. and Uchiyama, M. (2011) Efficacy and Safety of Ramelteon in Japanese Adults with Chronic Insomnia: A Randomized, Double-Blind, Placebo-Controlled Study. Expert Review of Neurotherapeutics, 11, 215-224. http://dx.doi.org/10.1586/ern.10.197

[66] Uchiyama, M., Hamamura, M., Kuwano, T., Nagata, H., Hashimoto, T., Ogawa, A. and Uchimura, N. (2011) LongTerm Safety and Efficacy of Ramelteon in Japanese Patients with Chronic Insomnia. Sleep Medicine, 12, 127-133. http://dx.doi.org/10.1016/j.sleep.2010.10.006

[67] Pandi-Perumal, S.R., Srinivasan, V., Poeggeler, B., Hardeland, R. and Cardinali, D.P. (2007) Drug Insight: The Use of Melatonergic Agonists for the Treatment of Insomnia-Focus on Ramelteon. Nature Clinical Practice Neurology, 3 , 221-228. http://dx.doi.org/10.1038/ncpneuro0467

[68] Lam, R.W. (2006) Sleep Disturbances and Depression: A Challenge for Antidepressants. International Clinical Psychopharmacology, 21, S25-S29. http://dx.doi.org/10.1097/01.yic.0000195658.91524.61

[69] Kupfer, D.J. (2006) Depression and Associated Sleep Disturbances: Patient Benefits with a Gomelatine. European Neuropsychopharmacology, 16, S639-S643. http://dx.doi.org/10.1016/S0924-977X(06)70010-4

[70] Guttuso, T. (2012) Effective and Clinically Meaningful Non-Hormonal Hot Flash Therapies. Maturitas, 72, 6-12. http://dx.doi.org/10.1016/j.maturitas.2012.01.023

[71] Eichling, P.S. and Sahni, J. (2005) Menopause Related Sleep Disorders. Journal of Clinical Sleep Medicine, 1, 291300.

[72] Wafford, K. and Ebert, B. (2008) Emerging Anti-Insomnia Drugs: Tackling Sleeplessness and the Quality of Wake Time. Nature Reviews Drug Discovery, 7, 530-540. http://dx.doi.org/10.1038/nrd2464

[73] Millan, M.J., Gobert, A., Lejeune, F., Dekeyne, A., Newman-Tancredi, A., Pasteau, V., Rivet, J.M. and Cussac, D. (2003) The Novel Melatonin Agonist Agomelatine (S20098) Is an Antagonist at 5-Hydroxytryptamine2c Receptors, 
Blockade of Which Enhances the Activity of Frontocortical Dopaminergic and Adrenergic Pathways. Journal of Pharmacology and Experimental Therapeutics, 306, 954-964. http://dx.doi.org/10.1124/jpet.103.051797

[74] Bourin, M., Mocaer, E. and Porsolt, R. (2004) Antidepressant-Like Activity of S 20098 (Agomelatine) in the Forced Swimming Test in Rodents: Involvement of Melatonin and Serotonin Receptors. Journal of Psychiatry and Neuroscience, 29, 126-133.

[75] Bertaina-Anglade, V., La Rochelle, C.D., Boyer, P.A. and Mocaer, E. (2006) Antidepressant-Like Effects of Agomelatine (S 20098) in the Learned Helplessness Model. Behavioural Pharmacology, 17, 703-713. http://dx.doi.org/10.1097/FBP.0b013e3280116e5c

[76] Fuchs, E., Simon, M. and Schmelting, B. (2006) Pharmacology of a New Antidepressant: Benefit of the Implication of the Melatonergic System. International Clinical Psychopharmacology, 21, S17-S20. http://dx.doi.org/10.1097/01.yic.0000199456.39552.c7

[77] Millan, M.J. (2006) Multi-Target Strategies for the Improved Treatment of Depressive States: Conceptual Foundations and Neuronal Substrates, Drug Discovery and Therapeutic Application. Pharmacology \& Therapeutics, 110, 135-370. http://dx.doi.org/10.1016/j.pharmthera.2005.11.006

[78] Landolt, H.P. and Wehrle, R. (2009) Antagonism of Serotonergic 5-HT2A/2C Receptors: Mutual Improvement of Sleep, Cognition and Mood? European Journal of Neuroscience, 29, 1795-1809. http://dx.doi.org/10.1111/j.1460-9568.2009.06718.x

[79] Varcoe, T.J. and Kennaway, D.J. (2008) Activation of 5- $\mathrm{HT}_{2 \mathrm{C}}$ Receptors Acutely Induces Per1 Gene Expression in the Rat SCN in Vitro. Brain Research, 1209, 19-28. http://dx.doi.org/10.1016/j.brainres.2008.02.091

[80] Martin, J.R., Bos, M., Jenck, F., et al. (1998) 5-HT $2 \mathrm{C}$ Receptor Agonists: Pharmacological Characteristics and Therapeutic Potential. Journal of Pharmacology and Experimental Therapeutics, 286, 913-924.

[81] Detanico, B.C., Piato, A.L., Freitas, J.J., Lhullier, F.L., Hidalgo, M.P., Caumo, W. and Elisabetsky, E. (2009) Antidepressant-Like Effects of Melatonin in the Mouse Chronic Mild Stress Model. European Journal of Pharmacology, 607, 121-125. http://dx.doi.org/10.1016/j.ejphar.2009.02.037

[82] Mcelroy, S.L., Winstanley, E.L., Martens, B., Patel, N.C., Mori, N., Moeller, D., McCoy, J. and Keck, P.E. (2010) A Randomized, Placebo-Controlled Study of Adjunctive Ramelteon in Ambulatory Bipolar I Disorder with Manic Symptoms and Sleep Disturbance. International Clinical Psychopharmacology, 26, 48-53. http://dx.doi.org/10.1097/YIC.0b013e3283400d35

[83] Crupi, R., Mazzon, E., Marino, A., La Spada, G., Bramanti, P., Cuzzocrea, S. and Spina, E. (2010) Melatonin Treatment Mimics the Antidepressant Action in Chronic Corticosterone-Treated Mice. Journal of Pineal Research, 49, 123129.

[84] Srinivasan, V., Cardinali, D.P., Pandi-Perumal, S.R. and Brown, G.M. (2011) Melatonin Agonists for Treatment of Sleep and Depressive Disorders. Journal of Experimental and Integrative Medicine, 1, 149-158.

[85] Loo, H., Hale, A. and Dhaenen, H. (2002) Determination of the Dose of Agomelatine, a Melatoninergic Agonist and Selective 5- $\mathrm{HT}_{2}$ Cantagonist, in the Treatment of Major Depressive Disorder: A Placebo-Controlled Dose Range Study. International Clinical Psychopharmacology, 17, 239-247. http://dx.doi.org/10.1097/00004850-200209000-00004

[86] Kennedy, S.H. and Emsley, R. (2006) Placebo-Controlled Trial of Agomelatine in the Treatment of Major Depressive Disorder. European Neuropsychopharmacology, 16, 93-100. http://dx.doi.org/10.1016/j.euroneuro.2005.09.002

[87] Calabrese, J.R., Guelfi, J.D. and Perdrizet-Chevallier, C. (2007) Agomelatine Adjunctive Therapy for Acute Bipolar Depression: Preliminary Open Data. Bipolar Disorders, 9, 628-635. http://dx.doi.org/10.1111/j.1399-5618.2007.00507.x

[88] Llorca, P.M. (2010) The Antidepressant Agomelatine Improves the Quality of Life of Depressed Patients: Implications for Remission. Journal of Psychopharmacology, 24, 21-26. http://dx.doi.org/10.1177/1359786810372978

[89] Di Giannantonio, M., Di Iorio, G., Guglielmo, R., De Berardis, D., Conti, C.M., Acciavatti, T., Cornelio, M. and Martinotti, G. (2011) Major Depressive Disorder, Anhedonia and Agomelatine: An Open-Label Study. Journal of Biological Regulators and Homeostatic Agents, 25, 109-114.

[90] Lopes, M.C., Quera-Salva, M.A. and Guilleminault, C. (2005) Cycling Alternating Pattern in the NREM Sleep of Patients Within Major Depressive Disorder: Baseline Results and Change Overtime with a New Antidepressant. Sleep Medicine, 6, 87-88.

[91] Lopes, M.C., Quera-Salva, M.A. and Guilleminault, C. (2007) Non-REM Sleep Instability in Patients with Major Depressive Disorder: Subjective Improvement and Improvement of Non-REM Sleep Instability with Treatment (Agomelatine). Sleep Medicine, 9, 33-41. http://dx.doi.org/10.1016/j.sleep.2007.01.011

[92] Hardeland, R., Poeggeler, B., Srinivasan, V., Trakht, I., Pandi-Perumal, S.R. and Cardinali, D.P. (2008) Melatonergic Drugs in Clinical Practice. Arzneimittel-Forschung, 58, 1-10. 
[93] Kasper, S., Hajak, G., Wulff, K., et al. (2010) Efficacy of the Novel Antidepressant Agomelatine on the Circadian Rest-Activity Cycle and Depressive and Anxiety Symptoms in Patients with Major Depressive Disorder: A Randomized, Double-Blind Comparison with Sertraline. Journal of Clinical Psychiatry, 71, 109-120. http://dx.doi.org/10.4088/JCP.09m05347blu

[94] European Food Safety Authority (2011) Scientific Opinion on the Substantiation of a Health Claim Related to Melatonin and Reduction of Sleep Onset Latency (ID 1698, 1790, 4080) Pursuant to Article 13(1) of Regulation (EC) No 1924/2006. EFSA Journal, 9, 2241.

[95] Wilson, S.J., Nutt, D.J., Alford, C., Argyropoulos, S., Baldwin, D., Bateson, A., Britton, T., Crowe, C., Dijk, D.J., Espie, C., Gringras, P., Hajak, G., Idzikowski, C., Krystal, A., Nash, J., Selsick, H., Sharpley, A. and Wade, A. (2010) British Association for Psychopharmacology Consensus Statement on Evidence-Based Treatment of Insomnia, Parasomnias and Circadian Rhythm Disorders. Journal of Psychopharmacology, 24, 1577-1601.

http://dx.doi.org/10.1177/0269881110379307 